\title{
A (in)flexibilidade pragmática na fala da criança e os erros no processo de aquisição da linguagem
}

\author{
Irani Rodrigues Maldonade \\ Universidade Estadual de Campinas (UNICAMP), Campinas, São Paulo, Brasil \\ irani@fcm.unicamp.br \\ http://orcid.org/0000-0002-5607-7344
}

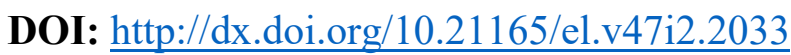

\section{Resumo}

O objetivo deste trabalho é analisar alguns erros no processo de aquisição da linguagem relacionados à aquisição do léxico e algumas expressões linguísticas na fala de crianças brasileiras. No interacionismo proposto por De Lemos (desde 1982), a linguagem não é reduzida ao papel de ferramenta social, puramente instrumental. Ela é a condição necessária para o processo de aquisição da linguagem, sendo o diálogo tomado como unidade de análise, de modo que a relação estrutural entre a fala da criança e seu(s) interlocutor(es) pode ser cotejada. Os resultados da análise de dados indicam que a linguagem deve ser "apre(e)ndida" na sua relação instável de interioridade e "exterioridade" no diálogo. Os erros na fala das crianças não tomam, necessariamente, o mesmo referencial já cristalizado pelos usos da língua adulta. Eles constituem o seu próprio eixo "provisório" para o estabelecimento de relação/identificação, ou seja, mostram a flexibilidade pragmática nas marcas do sujeito no seu processo de aquisição da linguagem.

Palavras-chave: aquisição da linguagem; erros; interacionismo; flexibilidade pragmática.

The pragmatic (in)flexibility in the child's speech and the errors in the language acquisition process

\begin{abstract}
The objective of this paper is to analyze some errors in the language acquisition process of Brazilian children related to the acquisition of the lexicon and some linguistic expressions. In the interactionism proposed by De Lemos (since 1982), language is not reduced to the role of social tool, purely instrumental. It is the necessary condition for the process of language acquisition and the dialogue is taken as the unit of analysis, so that the structural relationship between the child's speech and his interlocutor(s) can be shown. The results of data analysis indicate that language must be "grasped" in its unstable relationship of interiority and "exteriority" in dialogue. The errors in children's speech do not necessarily take the same referetional already crystallized by the uses of adult language. They constitute their own "provisional" axis for the establishment of relation/identification, that is, show the pragmatic flexibility in the marks of the subject in their process of language acquisition.
\end{abstract}

Keywords: language acquisition; errors; interactionism; pragmatic flexibility.

\section{Introdução}

Os estudos da linguagem têm experimentado atualmente uma renovada ênfase teórica em direção à investigação da língua em interação, relacionada às capacidades humanas de adaptação e seleção de expressões linguísticas e gestuais. Estas são também observadas ao longo do processo de aquisição da linguagem pelas crianças. Entretanto, 
considerar a dimensão social-pragmática, de modo geral, nas teorias em aquisição da linguagem não tem sido uma tarefa fácil. Segundo Tomasello (2000, p. 411), esta situação fica ainda mais comprometida quando se enfoca a aquisição do léxico e expressões linguísticas, porque os usos dessas estruturas linguísticas pelos falantes não são incluídos nas análises. Apesar de concordarmos com esta observação feita pelo autor, o quadro teórico ao qual este trabalho faz adesão é a teorização desenvolvida por De Lemos (desde 1982), que toma a interação como sendo a condição necessária para o processo de aquisição da linguagem.

Tal perspectiva interacionista privilegia a relação estrutural entre a fala da criança e a de seu interlocutor, de forma que o diálogo é tomado como unidade de análise. Além disso, essa teorização sempre rejeitou a análise da fala da criança através de categorias oferecidas pela descrição linguística. Dessa forma, os enunciados da criança não podem ser tomados como evidência de conhecimento categorial da língua. Ao lado disso, os erros na fala da criança são tomados como constitutivos do processo de aquisição da linguagem e encarados como "um processo original de constituição de significado, muitas vezes sem paralelo com a fala adulta", conforme apontado por Figueira $(1995,2010)$. Investigadores interacionistas, tais como De Lemos (1992, 2002), Castro (2006), Maldonade (2003, 2012 , 2014), entre outros, enxergam neste rico e extenso material um domínio apto a mostrar o processo de captura do sujeito pela língua(gem).

De modo geral, a linguagem pode ser definida como ação, nas perspectivas pragmáticas. Dessa forma, ela pode ser compatibilizada com propostas interacionistas no terreno da aquisição da linguagem, que entendem que o léxico é uma ferramenta a serviço de um sujeito para realização de suas intenções. Neste sentido, os usos linguísticos constituem sempre ações com propósito, cujas regras são estruturadas pelas experiências históricas, sociais e culturais. Apesar de não existir uma única definição de pragmática, e nem ser o escopo deste artigo demonstrar a compatibilidade da(s) pragmática(s) com propostas interacionistas em aquisição da linguagem, será possível perceber, ao longo do artigo, como ela pode ser alinhada à proposta interacionista desenvolvida por De Lemos e colaboradoras, ao lado do conceito de fala de Saussure (1972).

Quando se volta para a área de aquisição da linguagem, Bates (1974) assinala que podem ser observados três eixos de discussão relativos ao desenvolvimento da pragmática: a) em torno do desenvolvimento das funções comunicativas, ressaltando-se como as crianças são capazes de adquirir/lidar com grande variedade de expressões linguísticas; b) em torno de como as crianças respondem e percebem (situam-se) (n)a comunicação (interação) e suas consequências e c) em torno da maneira como a criança coopera na interação e conversação. De acordo com a proposta deste artigo, iremos nos concentrar mais no primeiro e segundo eixos.

Os eventos linguísticos dos quais as crianças participam durante o processo de aquisição da linguagem ocorrem num quadro de interação multidimensional envolvendo vários fatores, tais como: a troca de turnos dialógicos entre interlocutores, a seleção lexical, os objetivos do diálogo (assim como sua imprevisibilidade) e principalmente, a produção e interpretação de sentidos. Ou seja, os efeitos discursivos constituídos na dinâmica dos diálogos requerem da criança em processo de aquisição da linguagem uma constante adaptação à língua(gem) em funcionamento, que é aqui entendida como flexibilidade pragmática. 
Cabe salientar que algumas contribuições sobre o erro na aquisição lexical já foram oferecidas por investigadores interacionistas (v. FIGUEIRA, 2010). Elas se basearam no conceito de analogia de Saussure $(1972,2002)$ e assinalaram que as inovações lexicais na fala da criança mostram um modo singular de constituição de significado ao se valer das possibilidades que são dadas pela própria língua. Torna-se agora relevante chamar atenção para os aspectos ditos pragmáticos relacionados ao funcionamento da língua(gem) em situações nas quais se deve considerar quem fala, a quem se fala, as expectativas dos interlocutores na interação, ou seja, nos diferentes atos de fala que podem compor o diálogo criança-adulto. Xingar, duvidar, teimar, elevar o tom de voz estão entre eles. Propõe-se aqui observar como eles aparecem no processo de aquisição do léxico e de algumas expressões linguísticas.

Neste artigo, buscar-se-á dirigir um olhar mais detalhado para esta variedade de atos de fala e seus contornos mais ou menos flexíveis, atualizados nos enunciados da criança e seu(s) interlocutor(es). Tal olhar torna-se particularmente importante quando se quer entender o fenômeno de criação de palavras novas e expressões (que não estão presentes na fala dos adultos) registrado, predominantemente, entre 3 e 5 anos de idade na fala de crianças. Para tanto, serão analisados alguns erros na aquisição do léxico e algumas expressões linguísticas na fala de duas crianças brasileiras (A e M) entre 3 e 4 anos de idade.

Antes disso, é imprescindível a breve apresentação do quadro teórico interacionista, que embasa este trabalho, na próxima seção.

\section{Referencial teórico}

A teorização interacionista proposta por De Lemos (desde 1982), em todos os desdobramentos que sofreu ao longo dos últimos anos, tem procurado não deixar de lado nem o sujeito e nem a língua. Nessa teorização, os processos metafóricos e metonímicos propostos por De Lemos (1992) se mostraram adequados para demonstrar de que maneira as propriedades formais da linguagem (e da língua) podiam ser derivadas de processos de interação linguístico-discursivos. A partir disso, a descrição da fala da criança tem sido possibilitada pelo estruturalismo, enquanto programa teórico.

Essa teorização conseguiu explicar que um passo fundamental para a constituição da criança como sujeito falante é a conversão da fala do outro em discurso próprio. Segundo Castro (2006), a teorização interacionista propõe uma visão estrutural da mudança como sendo o fenômeno essencial da aquisição da linguagem. Para a autora, isso acontece porque o reconhecimento da ordem própria da língua, sustentada tanto por Saussure quanto por Chomsky, não pode ser sustentado a partir de uma visão desenvolvimentalista em aquisição da linguagem, conforme o que é proposto por De Lemos (2002). Sendo assim, esta autora rompe com a perspectiva desenvolvimentalista dominante na área, que trata a língua como um objeto estático e bem acabado. Além disso, De Lemos (2002) sustenta, coerentemente com a noção de autonomia da língua, a sua função como "captura".

A partir do conceito de captura é que De Lemos (2002) define o fenômeno da mudança que ocorre no processo de aquisição da linguagem, como "mudança de posição em uma estrutura". Ou seja, no percurso da criança de infans a sujeito falante ocorrem mudanças de posição da criança relativamente à fala do outro (chamada de primeira 
posição), à língua (chamada de segunda posição) e, consequentemente, à sua própria fala (chamada de terceira posição). Os erros na fala da criança - dados privilegiados para análise - também fazem parte desse percurso. É preciso deixar claro que os erros estão presentes durante todo processo de aquisição da linguagem, embora apareçam de forma mais concentrada num dado momento (na segunda posição), na explosão do vocabulário da criança no processo de aquisição do léxico, conforme os exemplos trazidos na próxima seção poderão ilustrar.

Figueira (2010, p. 115) afirma que "precisamos de bem pouco esforço de argumentação para introduzir o pensamento saussureano na abordagem dos fenômenos afeitos ao processo de aquisição da língua materna". Ressalta ainda que

[...] a força desse aparato teórico foi se mostrando como um caminho a ser seguido desde o momento em que, ingressando no universo empírico que elege o "erro" como dado de eleição, enfrentamos a necessidade de expor a maneira como a criança se encontra submetida à língua, em instâncias que permitem flagrar a condição de sujeito capturado pela língua (usa-se aqui o termo posto em circulação por De Lemos, a partir de 2002). (FIGUEIRA, 2010, p. 115).

De acordo com a teorização interacionista, não se pode ignorar a interpretação do adulto como fenômeno importante, que vem completar o fenômeno discursivo que temos a descrever e a explicar, como será visto, mais adiante neste artigo, na apresentação dos dados das crianças. Antes disso, será necessário dar esclarecimentos sobre como os dados da fala das crianças foram colhidos.

\section{Metodologia}

Ao iniciar esta seção, torna-se necessário fornecer algumas informações sobre a metodologia longitudinal observacional empregada nesta pesquisa qualitativa. Ela é a mesma metodologia desenvolvida e utilizada por outros investigadores da perspectiva teórica interacionista iniciada por De Lemos (1982).

Uma característica importante é o fato de os dados da fala das crianças serem colhidos em situações de diálogos espontâneos, no dia a dia delas com seus familiares. Desse modo, os dados são do tipo naturalístico.

Os dados de fala da primeira criança (M) foram colhidos em sessões de gravações semanais desde 1;6 (um ano e seis meses) até 4;6 (quatro anos e seis meses) de idade, com duração média de 45 minutos. Tanto a investigadora quanto os familiares participavam das sessões de gravação. M é a terceira filha (a caçula) de um casal de classe média paulista brasileira, em que o pai tinha nível de ensino superior incompleto e a mãe nível de ensino médio incompleto. $M$ apresentava boa saúde e não havia quaisquer queixas com relação ao seu desenvolvimento geral. A diferença de idade de $\mathrm{M}$ com suas irmãs era de 7 e 9 anos. Depois das gravações, foram realizadas as transcrições (largas) dessas sessões, suas revisões e, posteriormente, trechos foram selecionados para análise de dados, de acordo com o objetivo da pesquisa.

Além desses dados colhidos em sessões de gravação, outros dados foram anotados em um caderno diário pelos familiares, constituindo, assim, a segunda fonte de dados para a pesquisa. A investigadora solicitava aos familiares que anotassem os diálogos em que erros apareciam na fala de $\mathrm{M}$ e $\mathrm{A}$. A última criança conta apenas com dados registrados 
em diário. O material de $\mathrm{M}$ já foi bastante explorado em trabalhos anteriores, como o de dissertação de mestrado (MALDONADE, 1995), tese de doutorado (MALDONADE, 2003) e alguns artigos (MALDONADE, 2010, 2011, 2012 e 2014).

\section{Apresentação e discussão dos dados}

Dado o objetivo do artigo, que propõe lançar um olhar mais detalhado para a variedade de atos de fala e seus contornos mais ou menos flexíveis, atualizados nos enunciados das crianças e seu(s) interlocutor(es), serão apresentadas a seguir, algumas ocorrências na fala das crianças, que para os leigos podem parecer "estranhas", mas para os investigadores da área de aquisição da linguagem demandam uma análise, por deixar indicado uma condição especial da criança na língua(gem).

O primeiro episódio, abaixo, mostra que diante da materialidade sonora, resultado de uma escuta divergente, a fala do interlocutor adulto impõe uma reformulação na fala da criança, mostrando sua flexibilidade pragmática para que ela se faça entendida no diálogo.

4;1.19 (D) ${ }^{1}$ (em seu quarto, M estava montando um quebra-cabeça com sua irmã (Mari)).

M: Quero o tem!

Mari: Tem o quê?

M: O tem.

Mari: Não tem? (estranhamento)

M: Tem! (elevando seu tom de voz) Que faz piuí, piuí, piuí.

A ocorrência 1 mostra um trabalho diferenciado da criança com a língua. Inicialmente, Mari não entende a fala de $\mathrm{M}$, que solicita a peça do quebra-cabeça que representa o objeto (trem), que se encontrava ao lado dela. Por isso pergunta: "Tem o quê?" para M, que reafirma seu pedido, ao dizer "O tem.”. Novamente, Mari parece não entender a solicitação de M, ao expressar seu estranhamento ao dizer "Não tem?". Desta vez, M responde "Tem", elevando seu tom de voz, conferindo ênfase assertiva em seu enunciado, além de acrescentar "que faz piuí, piuí, piuí", reproduzindo em onomatopeia o barulho realizado pelo objeto (trem) que ela desejava obter.

Nota-se que a flexibilidade pragmática, por assim dizer, se mostra na fala de $\mathrm{M}$ na medida em que esta, para se fazer entender por Mari, eleva seu tom de voz e apela em reproduzir o som produzido pelo objeto (piuí, piuí, piuí), reformulando seu dizer. Mari, por sua vez, pareceu interpretar o "tem" da fala de M como verbo, pois pergunta "Tem o quê?" em seu primeiro enunciado, no episódio acima, e "Não tem?", no segundo. A imprecisão do sentido na fala de $M$ parecer surgir por conta do fonema /r/ que não é pronunciado por M, produzindo "tem" ao invés de "trem". Mesmo sem pronunciá-lo, a esta altura de seu processo de aquisição da linguagem, M se movimentou na língua(gem)

\footnotetext{
${ }^{1}$ Os números separados por ponto e vírgula, e depois por ponto, representam a idade da criança na ocorrência em questão. Assim, 4;1.19 significa: quatro anos, um mês e dezenove dias. Se depois dos números ainda aparecer a letra $\mathrm{D}$, entre parênteses, indica que o dado foi registrado no diário (a outra fonte de dados existente). Caso contrário, ele é de transcrição de sessão de gravação realizada com a criança. As outras abreviaturas referem-se à: investigadora (I), irmã mais velha de M (Dani), outra irmã, também mais velha do que M (Mari). Da outra criança (A), os dados são de diário. As abreviaturas referem-se à: investigadora (I) e mãe da criança (Ir).
} 
para que o sentido de seu enunciado fosse assegurado no diálogo, valendo-se, portanto, de recurso pragmático, que pudesse auxiliá-la em se fazer entender, ou seja, elevando seu tom de voz e reproduzindo em onomatopeia o ruído produzido pelo objeto que desejava obter. Ou seja, M já situada na terceira posição da criança no processo de aquisição da linguagem, não só recusa a interpretação feita por Mari de sua fala, como reitera seu pedido, indicando através de "piuí, piuí, piuí" que se referia ao objeto (trem) e não ao verbo (tem). De acordo com a proposta de De Lemos (2002), a criança situada na terceira posição passa a ter escuta para sua própria fala e, com isso, pode reformular o seu dizer. Ao passo que, se a criança estivesse situada na segunda posição, ela ainda não teria escuta para sua própria fala e estaria presa ao movimento da língua(gem).

Observa-se, neste episódio, que duas palavras são comparadas na fala de M: trem e tem, produzindo como efeito, não se pode negar, uma "análise" da língua realizada pela criança, que, naquele momento, não tinha como explicitá-la mobilizando uma metalinguagem. Não há como pressupor na criança, nessa idade, uma capacidade de explicitar a operação linguística do que aconteceu em sua fala. De acordo com Jakobson (1974), pode-se dizer que parte da mensagem remete ao código. Essa ocorrência mostra, de certa forma, um trabalho sofisticado da criança com a língua(gem), em que não há como subtrair seu efeito de "análise" com relação à língua, além da necessidade de obter o objeto desejado, ou seja, fazer-se entender, ser interpretada, dando prosseguimento ao diálogo. Foi a interpretação equivocada do interlocutor que oportunizou que as relações da língua fizessem eco na fala de $\mathrm{M}$.

Segundo De Lemos (1995), na área de aquisição da linguagem, assume-se que é "natural" e até mesmo necessário pesquisar sobre a aquisição da fonologia, sem passar os olhos pela sintaxe, ou estudar o desenvolvimento de um determinado subsistema morfológico, sem dar atenção à sua possível determinação fonológica. A autora ainda afirma que, na medida em que uma determinada teoria linguística é usada na descrição dos enunciados da criança, dela mesma parece vir a autorização de legitimidade dessa prática descritiva. Disso decorre que as questões centrais da teoria linguística ficam como que marginais, considerando-se o uso instrumental que se faz com a finalidade meramente descritiva. Soma-se a isso o fato de a noção de desenvolvimento impor à descrição uma ordenação do adquirido com base em seu grau de complexidade ou estatuto na teoria linguística. Desse modo, questões discursivas são remetidas para o momento posterior do processo de aquisição da linguagem, ou seja, depois de um conhecimento restrito ao domínio da sentença. Porém, para De Lemos (1995), o encadeamento e a imprevisibilidade da fala sempre produzem questão para a teoria linguística desde o estruturalismo europeu, ou seja, desde o momento em que se define a língua como um sistema que só conhece sua ordem própria. Isso porque é a fala que faz evoluir a língua.

Para chegar à definição de língua, Saussure (1972), numa atitude metodológica, exclui tudo o que pertence à fala, isto é, elimina aspectos discursivos que remetem à esfera individual. Mas o que é excluído retorna como indagação sobre o espaço livre que a língua deixa para o "próprio da fala". Segundo De Lemos (1995), o individual que retorna é definido como espaço não previsto, onde se pode exercer a liberdade das combinações. Em qualquer ponto da cadeia linguística, qualquer elemento pode abrir espaços para outros, o que significa que a estratificação da cadeia em palavras ou em frases corre sempre o risco de se desfazer ou refazer. Consequentemente, De Lemos (1995, p. 15) afirma que "a liberdade das combinações se reduz assim à escolha pelo indivíduo saussureano de um caminho dentre caminhos que ele não escolheu.". Quais seriam as 
consequências da possibilidade de irrupção do individual a cada ponto da cadeia linguística? De Lemos (1995) afirma que Saussure reconhece em parte essa dificuldade ao afirmar que "no domínio do sintagma não há limite categórico entre o fato de língua, testemunho do uso coletivo, e o fato de fala, que depende da liberdade individual" (Op. cit., p. 15).

De acordo com o quadro de Jakobson (1974), a próxima ocorrência (2) mostra duas situações no processo de aquisição da linguagem: a) aquela em que parte da mensagem remete ao código (já explorada em artigo anterior (MALDONADE, 2014)) e b) aquela em que parte da mensagem remete à própria mensagem, para a qual se dirige a atenção agora.

(2) 3;2.13 (montando quebra-cabeça no quarto de $\mathrm{M}$ )

I: Não qué cabê, $M$.

M: Ajuda então!

I: Como "ajuda então"?

M: Ajuda assim, cabe. (M forçou a peça em seu lugar no quebra-cabeça)

I: Como assim, M?

M: Cabí de coube.

I: Hum?

M: Cabí de coube.

Mari: Ela tem lógica!

M: Tem lógica.

I: Como é que faz?

M: Da próxima vez, vai falá isso pra sua vó.

I: Minha avó, Marcela?! Minha avó já morreu.

M: Tadê sua vó?

I: Morreu.

M: Aonde ela tá?

I: No cemitério.

M: Por quê?

I: Porque ela morreu, né.

Na ocorrência em questão, M solicitava que I a ajudasse a completar o quebracabeça que jogavam, em parceria com a irmã de M, Mari. M tinha forçado (feito caber à força) uma das peças do jogo de encaixe e, possivelmente, solicitava que I agisse de forma parecida. Nesse episódio, coloca-se em destaque a fala de M “cabí de coube", em resposta à pergunta de I (“Como assim, M?").

Diante do estranhamento de I, manifesto por "Hum?", M repete o que havia dito: "cabí de coube". Logo após, Mari, ao referir-se ao enunciado de M, diz: "Ela tem lógica!"; e essa sentença é recolocada na fala da criança. Na sequência, I pergunta "Como é que faz?" a M, que responde demonstrando irritação: "Da próxima vez, vai falá isso pra sua vó.”. 
Na ocorrência (2), observa-se que M está situada na segunda posição no processo de aquisição da linguagem, conforme a proposta de De Lemos (2002), que é caracterizada pelo aparecimento do erro na fala da criança e sua impermeabilidade à correção. Nesta posição, M mostra-se também presa ao movimento da língua. Entretanto, o que se destaca não é apenas a relação que a criança estabelece em sua fala entre as formas "cabí" e "coube". Nota-se que o enunciado final da criança produz, de certo modo, a suspensão do sentido da própria mensagem. Há um abalo no sentido, que a relação deixa à mostra os efeitos produzidos pelas interpretações que vão sendo construídas nos enunciados pela criança. M parece querer atingir (I), sua interlocutora (que insistentemente lhe fazia perguntas), ao dizer "Da próxima vez, vai falá isso pra sua vó."

Para Franchi (1992), a experimentação dinâmica do sujeito no diálogo se compreende apenas parcialmente quando a imaginamos num processo receptivo de adaptação a um conjunto de convenções que reproduzem esquemas de interação social bem-sucedida; ou quando a consideramos exclusivamente como servindo à reprodução, de sucessivas etapas quase contratuais da interlocução. Nesse sentido, é preciso lembrar aqui que o contexto e a situação da atividade linguística são somente "modos" - não menos discursivos - que apoiam a seleção lexical original da criança e o "xingamento" no final do episódio (“da próxima vez, vai falá isso pra sua vó”). Embora se manifeste como condição de desenvolvimento eficaz do discurso, a flexibilidade pragmática não é previsível. Isso por conta da criatividade e movimentação do sujeito na língua(gem).

A ocorrência, a seguir, mostra novamente a impermeabilidade da fala de $\mathrm{M}$ à correção, característica da segunda posição proposta por De Lemos (2002).

(3) 3;00.07 (Dani coloca uma peça de vestuário em M)

I: Não cabe mais, $M$ !

M: Assim.

I: Não cabe.

Dani: Não cabe. Você era muito pequenininha.

M: Eu não era!

Dani: Era!

M: Não ero.

Dani: Tô falando/ "Não ero!" Ai, que coisa feia!

I: Era sim! Cê

M: Não ero! (alto)

I: Era! Você era! (alto, tentando corrigir M)

M: Isso é palavrão?

Dani: Não é palavrão, só que tá errado.

M: Hã, SI (baixo)

I: A M era tão pequenininha!

M: E(pausa)ra, e não cabia isso.

Dani: Cabia? 
Na aquisição de linguagem, os erros na fala da criança ampliam o quadro empírico e levam o estudioso a considerar os aspectos ditos pragmáticos, que estão também em jogo quando eles acontecem. Na ocorrência em questão, em que M diz "ero", soa até engraçado, pois a criança chega a perguntar aos interlocutores se se tratava de palavrão, dada sua posição de não escuta da língua. A repetição de "não ero" na fala de Dani, seguida do julgamento "Ai, que coisa feia!" e de "Era sim!" (da fala de I) parecem contribuir para que $\mathrm{M}$ atribuísse um sentido negativo à sua própria fala. Em outras palavras, os efeitos (pragmáticos) produzidos pela fala de $\mathrm{M}$ em seus interlocutores levaram-na a crer que estivesse produzindo um palavrão, quando, na verdade, eles estavam tentando corrigir a fala da criança, que apresentava um erro de flexão verbal, ao dizer "ero" ao invés de "era" (a forma esperada, de acordo com a língua adulta).

A próxima ocorrência trazida para a discussão foi flagrada num diálogo doméstico, do qual a criança (A) participava.

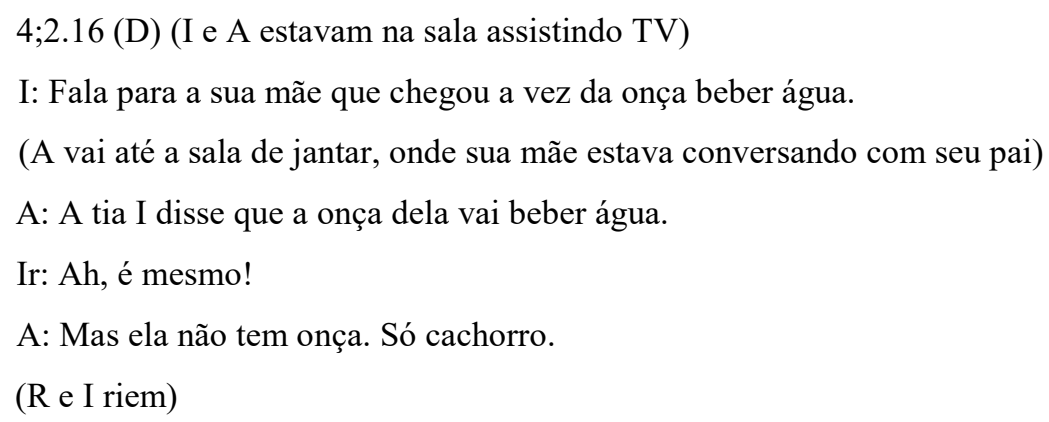

A ocorrência 4 mostra que A é sensível ao pedido de I, na medida que tenta transmitir a mensagem (recado) para sua mãe, Ir. No seu processo de aquisição da linguagem, a criança faz movimentos em direção à língua e também em direção à linguagem. Os sons da "fala" incipiente da criança são constituídos (recobertos) no diálogo por outro sentido, ou seja, como um possível de língua. Observa-se que a expressão "chegou a vez da onça beber água" (em que se anuncia que chegou a vez de alguém fazer algo) é metafórica. Na ocorrência em questão, A. pareceu desconhecer esse uso em sua língua materna, uma vez que disse "a onça dela vai beber água" e depois "Mas ela não tem onça. Só cachorro.”. Dada a condição de não escuta para a língua, em que a criança não consegue reformular o seu dizer, observa-se que A situa-se na segunda posição da criança no processo de aquisição da linguagem, conforme a proposta de De Lemos (2002). A criança não conseguiu entender o sentido da expressão usada por sua tia, tendo provocado o riso das interlocutoras adultas. Além disso, não conseguiu entender que o que estava em questão era o fato de a tia não cozinhar naquele dia, pois isso era um significado construído e partilhado entre sua mãe e I. Esta ocorrência mostra que o simples encadeamento de elementos da língua não é, neste caso, suficiente para dar conta da significação e do funcionamento linguístico.

De acordo com a visão crítica de Franchi (1992) sobre as teorias de linguagem que privilegiam a comunicação, pode-se dizer que o problema central é o da "significação" concebida não só como uma propriedade das expressões, apreensível pela enumeração de características sintáticas e morfológicas da língua, mas como um "ato", um ato intencional e motivado que põe em relação, de um lado, os interlocutores, de outro 
os elementos convencionais de que se servem na interlocução (a "função" específica a que se visa em cada ato de comunicação e a "forma" das expressões). Pensando assim, a correlação entre estrutura semântica e estrutura sintática descrever-se-ia pela representação explícita, de acordo com Franchi (1992) das condições mesmas do ato da comunicação, das intenções ou funções desses atos. Na ocorrência 4, isso fica evidente na medida em que $M$ pareceu desconhecer o sentido metafórico da expressão "chegou a vez da onça beber água", que fica destacado na fala seguinte da criança, quando tem que retomar o sentido do enunciado de I ("Fala para a sua mãe que chegou a vez da onça beber água."), colocando-o numa estrutura de discurso indireto, ao dizer "A tia I disse que a onça dela vai beber água". Sendo assim, embora a sentença manifesta na fala de M esteja "bem formada" do ponto de vista sintático, o mesmo não se pode afirmar com relação ao ponto de vista pragmático, pois ela coloca em risco a significação. Por isso, Franchi (1992) afirma que o problema central das teorias que privilegiam a comunicação é a significação. Sendo assim, a ocorrência em questão é exemplar no sentido de poder mostrar a inflexibilidade pragmática manifesta da fala de M. Neste sentido, observa-se que a significação relaciona-se fortemente com os usos da língua, que vão sendo estabelecidos pelos falantes nas interações das quais eles participam.

Fato é que não se chega aos sentidos d(n)a língua, senão pela fala, no processo de aquisição da linguagem. Com isso, pode-se perfeitamente entender porque os conceitos de língua e fala são propostos como interdependentes em Saussure. Vale, portanto,

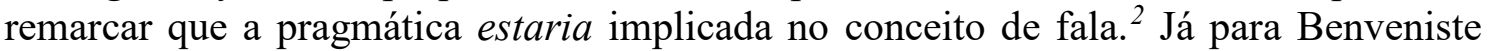
(1995), é no discurso atualizado em frases que a língua se forma e se configura. Por isso, o autor afirma que é neste lugar que se começa a linguagem.

\section{À guisa de conclusão}

A pragmática propõe um novo olhar sobre a língua, de modo que a relação dos usuários (falantes) com a língua(gem) possa ser problematizada. Assim, a situação discursiva e o sujeito passaram a ser componentes imprescindíveis para a construção do sentido dos enunciados. Com isso, é possível também deduzir que a pragmática opõe-se à concepção de linguagem definida apenas como espelho do pensamento, ou determinada biologicamente, o que permite aproximá-la do lugar ocupado pela fala na teorização interacionista desenvolvida por De Lemos e colaboradoras.

Portanto, conceber a língua no seu dinamismo, na sua heterogeneidade (nas características que lhe são próprias) significa também admitir que seus contornos não são muito nítidos, como faz o interacionismo. Pode-se concluir que a língua, se tomada como um conjunto de relações destituído de toda concretude, descrita como se fosse um objeto, não permite tocar na questão que, para a aquisição da linguagem, é fundamental: a relação da criança com sua língua, no que diz respeito à sua estruturação enquanto falante.

\footnotetext{
${ }^{2}$ De acordo com Dascal (1982), uma origem para a Pragmática pode ser encontrada nos estudos de Saussure (1972), que propôs o estudo da língua como objeto da Linguística, deixando a fala para as outras ciências, entre elas, a Pragmática, que tem como objeto de investigação o uso da língua pelos interlocutores. Sendo assim, a Pragmática teria o status de ciência, não podendo ser mais considerada como apenas um dos níveis de análise linguística.
} 
O tema envolvendo os erros na aquisição do léxico já foi abraçado anteriormente por pesquisadores interacionistas, principalmente Figueira $(1995,2010)$. No entanto, a atenção esteve voltada mais ao léxico em si e menos aos efeitos produzidos pela movimentação da criança e funcionamento linguístico no processo de aquisição da linguagem. De algum modo, este artigo tentou suprir esta lacuna ao focalizar esses aspectos pragmáticos e seus contornos mais ou menos flexíveis, atualizados nos enunciados da criança e seu(s) interlocutor(es), na composição do diálogo criança-adulto.

$\mathrm{Na}$ primeira ocorrência, a flexibilidade pragmática se mostrou na fala de $\mathrm{M}$ na medida em que esta, para se fazer entender no diálogo, elevou seu tom de voz e reproduziu, em onomatopeia (piuí, piuí, piuí), o som do objeto (trem) que desejava obter, uma vez que não conseguia pronunciar $\mathrm{o} / \mathrm{r} / \mathrm{ha}$ palavra em questão. Ficou evidente $\mathrm{o}$ trabalho sofisticado da criança com a língua(gem), que já situada na terceira posição da criança no processo de aquisição da linguagem, de acordo com De Lemos (2002), não só consegue escutar sua própria fala, mas também reformular o seu dizer. A flexibilidade se manifestou quase como condição de desenvolvimento eficaz do discurso. E por conta da imprevisibilidade da movimentação do sujeito na língua(gem) e sua criatividade, em mobilizar outro recurso linguístico (no caso, a onomatopeia), para se fazer entender, foi possível atestar, neste caso, que a flexibilidade pragmática não tem limites.

Já as ocorrências 2, 3 e 4 poderiam até ser analisadas baseando-se numa descrição dos "atos de fala", como proposto por Searle, ou ainda levando-se em consideração os princípios quase contratuais que regem a intenção comunicativa, privilegiando-se a noção de "comunicabilidade", as máximas de Grice, ou mesmo levando-se em consideração os papéis específicos dos sujeitos no diálogo. Enfim, nosso objetivo neste artigo não foi o de esgotar todas as possibilidades descritivas de interpretação.

$\mathrm{Na}$ ocorrência 3, a inflexibilidade pragmática na fala de M (situada na segunda posição) se mostra no momento em que os efeitos produzidos por sua fala em seus interlocutores levaram-na a crer que estivesse falando um palavrão, quando, na verdade, eles estavam tentando corrigir a fala da criança, que apresentava um erro de flexão verbal, ao dizer "ero" ao invés de "era". A ocorrência 4, por sua vez, é exemplar no sentido de mostrar a inflexibilidade pragmática na fala de $\mathrm{M}$, ao desconhecer o sentido metafórico da expressão "chegou a vez da onça beber água". Além disso, revela que os encadeamentos de elementos da língua, por si só, não são suficientes para dar conta da significação. O pequeno conjunto de dados aqui analisados não permite concluir que haja uma relação direta entre flexibilidade pragmática e posição ocupada pela criança no processo de aquisição da linguagem de acordo com De Lemos (2002). Para isso, seria necessário analisar um conjunto maior de dados.

Por ora, cabe assinalar que uma teoria da linguagem fundada em noções como "comunicação", "intenção", "função" social, opta também por uma gramática "vista como exterior e pública, como prática aberta e social", em que o esforço teórico se desloca à determinação das condições do exercício social da linguagem, derivadas de um princípio geral determinante - o da "comunicabilidade", "como única pertinência para uma teoria que recupere o fenômeno linguístico ao nível da realização", segundo Franchi (1992, p. 11). Dito de outro modo, conforme apontado pelo autor (Ibidem, p. 12) "desaconselha-se buscar a explicação da significação pela explicitação da estrutura das línguas naturais, mesmo quando se insiste em suas propriedades formais universais" (para quem nelas acredita!), porque são as necessidades da comunicação, suas funções e 
condições, identificáveis em um outro universo nocional, que determinam a estrutura linguística.

Os resultados da análise de dados deste trabalho indicam que a linguagem deve ser "apre(e)ndida" na sua relação instável de interioridade e "exterioridade" no diálogo. Os erros na fala das crianças mostram que elas não tomam, necessariamente, o mesmo referencial já cristalizado pelos usos da língua adulta. Eles podem constituir o seu próprio eixo "provisório" no estabelecimento de relação/significação, sendo possível surpreender o início do jogo ininterrupto da língua(gem) em funcionamento e seus efeitos, que deixam ver as marcas do sujeito no processo de aquisição da linguagem.

De acordo com De Lemos (1995, p. 15), "para Saussure, o indivíduo está sempre submetido a um funcionamento da língua, já que restrição e imprevisibilidade não se distribuem de forma desigual entre fonema e palavra, sentença e texto". Portanto, a tarefa em aquisição da linguagem não é descrever a língua ou a fala da criança, é descrever e interpretar a relação da criança com a língua a partir de sua fala.

\section{REFERÊNCIAS}

BATES, E. The acquisition of pragmatic competence. Journal of Child Language, v. 1, n. 2, p. 277-282, 1974.

BENVENISTE, E. Problemas de Linguística Geral I. 4. ed. Campinas: Editora da UNICAMP, 1995.

CASTRO, M. F. P. Sobre o (im)possível esquecimento da língua materna. In: LIER-DEVITTO, M. F.; ARANTES, L. (Orgs.). Aquisição, Patologias e Clínica de linguagem. São Paulo: Editora PUC-SP EDUC, 2006. p. 135-148.

DASCAL, M. Fundamentos metodológicos da Linguística. Pragmática. v. IV. Campinas: Editora da UNICAMP, 1982.

DE LEMOS, C. G. Sobre a aquisição da linguagem e seu dilema (pecado) original. Boletim da Abralin, n. 3, p. 97-126, 1982.

Los processos metafóricos y metonímicos como mecanismo de cambio. Substratum, n. 1, p. 121-135, 1992.

. Língua e discurso na teorização sobre aquisição da linguagem. Letras de Hoje, Porto Alegre, v. 30, n. 4, p. 9-28, 1995.

Das vicissitudes da fala da criança e de sua investigação. Cadernos de Estudos Linguísticos, Campinas, n. 42, p. 41-69, 2002.

FIGUEIRA, R. A. A Palavra divergente. Previsibilidade e imprevisibilidade nas inovações lexicais na fala de duas crianças. Trabalhos em Linguística Aplicada, v. 26, p. 49-80, 1995.

. O que a investigação sobre o erro na fala da criança deve a Saussure. Cadernos de Estudos Linguísticos, Campinas, v. 52, n. 1, p. 115-143, 2010.

FRANCHI, C. Linguagem: atividade constitutiva. Cadernos de Estudos Linguísticos, Campinas, v. 22, p. 9-39, 1992. 
JAKOBSON, R. Ensayos de Linguística General. Tradução de J. Pujol e J. Cabanes. Barcelona: Editorial Seix Barral, 1974.

MALDONADE, I. R. Erros na aquisição de verbos com alternância vocálica: uma análise sócio-interacionista. 1995. 210 f. Dissertação (Mestrado em Linguística) Instituto de Estudos da Linguagem, Universidade Estadual de Campinas, Campinas, 1995.

Erros na aquisição da flexão verbal: uma análise interacionista. 2003. $167 \mathrm{f}$. Tese (Doutorado em Linguística) - Instituto de Estudos da Linguagem, Universidade Estadual de Campinas, Campinas, 2003.

Erros na aquisição da flexão verbal: reflexividade e constituição do paradigma verbal. Estudos Linguísticos, São Paulo, v. 39, n. 2, p. 462-476, 2010.

Algumas considerações sobre o erro e a autocorreção no processo de aquisição da linguagem. Estudos Linguísticos, São Paulo, v. 40, n. 2, p. 539-552, 2011.

O erro e a autocorreção na relação da criança com a língua. Estudos Linguísticos, São Paulo, v. 41, n. 2, p. 403-418, 2012.

. Instâncias da língua na fala da criança. Estudos Linguísticos, São Paulo, v. 43, p. 666-678, 2014.

SAUSSURE, F. Curso de Linguística Geral. São Paulo: Cultrix, 1972.

. Escritos de Linguística Geral. Organizado e editado por Simon Bouquet e Rudolf Engler. São Paulo: Cultrix, 2002.

TOMASELLO, M. The social-pragmatic theory of word learning. Pragmatics, v. 10, n. 4, p. 401-413, 2000.

Recebido em: 01/10/2017

Aprovado em: 15/12/2017 